\title{
Üniversite Öğrencilerinde Duygusal Zekâ ve Yaşam Doyumu: Yaşamda Anlamın Aracı Rolü
}

\section{Emotional Intelligence and Life Satisfaction on University Students: Mediation Role of Meaning of Life}

\author{
Aslı KARTOL ${ }^{1}$, Ayşegül ERÇEVIK ${ }^{2}$
}

\section{Öz}

Bu çalışmanın amacı üniversite öğrencilerinde duygusal zekâ ile yaşam doyumu arasındaki ilişkide yaşamda anlamın aracı rolünü incelemektir. Araştırmanın çalışma grubunu basit seçkisiz örnekleme yoluyla 2018-2019 güz döneminde Amasya Üniversitesi Eğitim Fakültesi'nde öğrenim gören \% 74.7 ( $n=295)^{\prime} i$ kadın ve \% 24.8 ( $n=98$ )'i erkek olan 395 öğrenci oluşturmaktadır. Katılımcıların yaş aralığı 17 ile 34 yaş aralığında olup, yaş ortalamaları 20.62 (S.s: 1.78) 'dir. Araştırmada Schutte v.d. (1998) tarafından geliştirilen Göçet (2006) tarafından Türkçeye uyarlanan "Schutte Duygusal Zekâ Ölçeği", Diener (1984) tarafından geliştirilen ve Köker (1991) tarafından Türkçe'ye uyarlanan "Yaşam Doyumu Ölçeği" ve Steger, Frazier, Oishi ve Kaler (2006) tarafından geliştirilen ve Dursun (2012) tarafından Türkçe' ye uyarlanan "Yaşamın Anlamı Anketi" kullanılmıştır. Araştırmada yapılan istatistiki analizler sonucunda duygusal zekâ ile yaşam doyumu arasındaki ilişkide yaşamda anlamın boyutlarından yaşamda anlamın varlığının tam aracı bir değişken olduğu görülmüştür. Bu sonuçlara göre, duygusal zekâ düzeyi yüksek olan üniversite öğrencilerinin yaşamda anlamın varlığı puanlarının ve yaşam doyumlarının yüksek olduğu ortaya çıkmıştır.

Anahtar Kelimeler: Duygusal zekâ, yaşam doyumu, yaşamın anlamı, yaşamın amacı, yaşamda anlam arayışı.

\section{Abstract}

The aim of this study was to analyze the mediation role of meaning in life in the context of the relationship between the university students' emotional intelligence and their satisfaction with life. The population of the study, had been determined using simple random sampling, consisted of a total of 395 participants, studying in Amasya University Faculty of Education, $74.7 \%(n=295)$ whereof was female whereas $24.8 \%(n=98)$ was male. The ages of the participants ranged from 17 to 34 and average of their ages was 20.62 (S.d: 1.78). In the study, the Schutte The Emotional Intelligence Scale by Schutte et.al. (1998), adapted in Turkish Language by Göçet (2006), the Satisfaction with Life Scale by Diener (1985), adapted in Turkish Language by Köker (1991), and the Meaning in Life Questionnaire by Steger et.al., adapted in Turkish Language by Dursun (2012), were used. The results of the statistical analysis indicated that the Presence of Meaning, a subscale of the Meaning in Life Questionnaire, was a fully mediated variable in the relationship between emotional intelligence and their satisfaction with life. To these results, the higher the emotional intelligence of university students was, the higher their scores in the Presence of Meaning in Life Subscale and the higher satisfaction with life were.

Keywords: Emotional intelligence, satisfaction with life, meaning in life, purpose of life, seeking of meaning in life. 


\section{Extended Abstract}

Introduction: Technology, advancing each day, comes with many innovations, which in turn comes with numerous problems. It is important that people have positive perception of life against these innovations and problems. In this case, the concept of "positive psychology", which is popular and has a growing impact in the world, nowadays, and on which there have been increasing number of studies, takes the stage (Linley, 2009). "Emotional Intelligence" (EQ), one of the concepts of positive psychology was first put forward by Mayer and Salovey in 1990. Emotional intelligence is a broad concept consisting of the ability of individuals to control, comprehend, and be aware of their emotions, as well as the ability to identify and comprehend other individuals' emotions and to exploit these skills in favor of themselves and others. Goleman particularly emphasized that emotional intelligence, in other words the ability to manage the emotions, is a skill that can be improved (Goleman, 2010). The satisfaction with life, another concept of positive psychology, has been recently associated with psychological well-being, in other words "happiness". It can be said that this concept is an expression of cognitive evaluation of an individual's quality of life (Paschali ve Tsitsas, 2009). Seeking for a purpose of life, developing, maintaining and sustaining a purpose are important for an individual's happiness and peacefulness. Frankl (1978) suggested that seeking for a meaning is a fundamental source of motivation for individuals and it is not only important for well-being but also for survival. It was emphasized that the meaning is a central aspect for human development and has an identifying nature for personality (Weinstein, Ryan and Deci, 2012). Researches indicate that people tend to achieve satisfaction with life, positive effect, subjective well-being and mental and emotional health when they have a purpose of life and attribute a meaning to life (Chamberlain and Zika, 1992). Based on these, with this study, it was aimed to test the model on the intermediary role of meaning in life in the context of the relationship between the university students' emotional intelligence and their satisfaction with life.

Method: The population of the study, had been determined using simple random sampling, consisted of a total of 395 participants, students studying in Amasya University Faculty of Education in the academic year of 2018 - 2019, 74.7\% ( $n=295$ ) whereof was female whereas $24.8 \%(n=98)$ was male. The ages of the participants ranged from 17 to 34 and average of their ages was 20.62 (S.d. 1.78). In the study, the Schutte The Emotional Intelligence Scale by Schutte et.al. (1998), adapted in Turkish Language by Göçet (2006), The Satisfaction with Life Scale by Diener (1985), adapted in Turkish Language by Köker (1991), and the Meaning in Life Questionnaire by Steger et.al., adapted in Turkish Language by Dursun (2012), were used. All statistical data were processed on SPSS 20.0. Before statistical analysis was conducted, the reliability of the data, the lost and conflicting data and the assumptions of statistical analysis used were examined in parallel with the suggestions by Tabachnick and Fidell (2014). Descriptive statistics were used to inform about the socio-demographic backgrounds of the participants. The relationships between all variables were analyzed through Pearson Correlation Coefficient and Hierarchical Regression Analysis. Finally, the mediation role of Presence of Meaning in Life subscale of The Meaning in Life Questionnaire was tested using SPSS Process Macro, Model 4. To test the hypothesis during the statistical analysis a significance level of .05 was used.

Findings: It had been found out that emotional intelligence is a significant predictor of the presence of meaning in life, a subscale of the meaning in life, and satisfaction with life, whereas there was no significant correlation between emotional intelligence and seeking for a meaning life, another subscale of the meaning in life. Additionally, the presence of meaning in life had been found to be a significant predictor of satisfaction with life. Finally, it had been found out that the presence of meaning in life a mediation variable in the relation between emotional intelligence and the satisfaction with life.

Conclusions: This study was conducted to analyze the mediation role of presence of and seeking for meaning in life, two subscales of meaning in life, in the context of the relationship between emotional intelligence and their satisfaction with life. The correlation values obtained suggested that there is no relationship between the emotional intelligence and seeking for meaning in life, the subscale of meaning in life. The research results obtained in an examination based on the mediation role of presence of meaning in life in the context of the relationship between the emotional intelligence and satisfaction with life, suggested that the presence of meaning in life subscale was a fully mediated variable in the relationship between emotional intelligence and satisfaction with life. To these results, the higher the emotional intelligence of university students was, the higher their scores in the Presence of Meaning in Life Subscale and the higher satisfaction with life were.

Suggestions: This research was limited to young adult individuals who are studying in college level. It was interesting that the results obtained from this population can be generalized for the same-age individuals with different educational background within Turkey-wide sample. Similarly, it is considered that the model that was examined could be used in samples of different age-groups. In parallel with the results obtained, it is also considered that group studies towards improving emotional intelligence may have a positive effect in achieving a meaning in life, and therefore, the satisfaction with life, and in turn, may increase the number of factors to be protected against potential mental health risks. 


\section{Giriş}

Her geçen gün büyüyen, gelişen, ilerleyen teknoloji ile birlikte birçok yeni problem bu yeniliklere eşlik etmektedir. Bireyin tüm bu yeniliklere ve sorunlara karşı hayata olumlu bir bakış açısının olması oldukça önemlidir. Bu noktada devreye son yıllarda oldukça popüler olan, üzerinde çalışmaların her geçen gün arttığı ve tüm dünyaya yayılan "pozitif psikoloji" kavramı girmektedir (Linley, 2009). Seligman ve Csikszentmihalyi 2000 yılında yayınladıkları makalelerinde pozitif psikolojinin üç farklı odağından bahsetmiş ve bu odakları; olumlu öznel deneyim, olumlu bireysel özellikler, değerler ve onları destekleyen kurumlar olarak tanımlamışlardır. Pozitif psikolojide temel amaç; zayıfıkları onarmak yerine olumlu özellikleri arttırmaya odaklanmaktır (Clonan, Chafouleas, McDougal ve RileyTillman, 2004). Yine eğitimde toplumları, okulları, öğretmenleri ve geleceğin öğrencilerini yeniden organize edebilmek adına pozitif psikolojiden yararlanmak için büyük bir potansiyelin olduğu öngörülmektedir (Donaldson, Csikszentmihalyi ve Nakamura, 2011).

Dünya Ekonomik Formu 2018 verilerine göre 1701 yılında kurulan Yale Üniversitesinde verilmeye başlayan "Psikoloji ve İyi Yaşam" adlı pozitif psikoloji konularını ele alan dersin, üniversite tarihinin bugüne kadar yapılan en kalabalık (1200 kişi) ve en popüler dersi olduğu kayıtlara geçmiştir. Bu dersi veren Psikoloji Profesörü Laurie Santos, öğrencilerin artık son zamanlarda çok fazla depresif ve kaygılı oldukları, mutluluğun kaynaklarını bilimsel yönden öğrenmek istediklerini dile getirmiştir (Moore, 2018). Pozitif psikoloji özellikle kişiyi mutlu eden ve yaşamına değer katan özellikler üzerinde durmaktadır. Bu alanın çerçevesi hızla genişlemekte ve sevmek, duygusal zekâ, yaratıcılık gibi mutluluğun belirleyicileri olarak elen alınan daha birçok kavram ve çok fazla konuyu içine alarak büyümektedir (Seligman ve Csikszentmihalyi, 2000).

Pozitif psikoloji kavramlarından olan "duygusal zekâ" (EQ) 1990 yılında Mayer ve Salovey tarafından yayınlanan bir makale ile ilk kez literatüre girmiş fakat; Daniel Goleman'ın 1995 yılında yazmış olduğu "Duygusal Zekâ" adlı kitapta dikkatleri üzerinde toplamıştır. Duygusal zekâ kavramı kişinin kendi duygularını kontrol edebilmesi, anlaması ve farkında olması ile birlikte; başkalarının duygularını tanımlayıp anlayabilme ve bu becerileri hem kendi hem de başkalarının başarısı için kullanabilme yeteneğini içeren geniş kapsamlı bir kavramdır. Goleman duygusal zekânın yani duyguları yönetmenin bir yetenek olduğunu ve geliştirilebilen bir yapıya sahip olduğunu özellikle vurgulamıştır (Goleman, 2010). Yine duygusal zekânın akademik başarı dahil olmak üzere hayattaki başarının belirleyiciliğinin IQ' dan daha önemli olduğu öne sürülmüştür. EQ 'nun öğretilebilir olduğu fikri eğitim literatüründe okulların müfredatına eklenebilmesi hususunda yankı uyandırmıştır. Özellikle 2000'li yılların başlamasıyla birlikte duygusal ve sosyal yetkinliğin önemi üzerindeki araştırmalar artmıştır. (Parker, Saklofske, Wood ve Collin, 2009). Maddux (2018) insanların diğer kişilerle olan ilişkilerinin kalitesinin yaşam doyumları ve iyi oluşlarında oldukça önemli bir etkene sahip olduğunu dile getirmiştir. İlişkilerin pozitif psikolojinin de son zamanlarda üzerinde önemle durduğu kavramlardan olan yaşam doyumu üzerindeki etkisi düşünüldüğünde; duyguları ve ilişkileri yönetme temelli olan duygusal zekâ kavramının ele alınması gereken bir kavram olduğunu söylemek mümkündür. Anlatılanlar ışığında duygularını iyi bir şekilde yönetebilen kişilerin daha mutlu olup daha sağlıklı kararlar alabileceği düşünüldüğünden; kişinin duygusal zekâsının artması ile yaşamdan daha fazla doyum alması beklenmektedir.

Yaşam doyumu kavramı son yıllarda psikolojik iyi oluş yani "mutluluk" ile oldukça fazla birlikte anılan kavramlarından biridir. Bu kavram kişinin yaşam kalitesinin bilişsel değerlendirmesini ifade etmektedir (Paschali ve Tsitsas, 2010). Bir başka deyişle kişinin hayattan beklediği ile elinde var olanın karşılaştırılmasının sonucudur (Bilir ve Subaşı, 2006). Bireylerin yaşam doyumları ne kadar fazla ise, hayata bakışları o düzeyde pozitif olmakla birlikte, yaşadıklarından haz alma ve mutlu olma kapasitesi de aynı oranda artmaktadır.

Bir yaşam amacının peşinden koşma, geliştirme ve sürdürme mücadelesi, insanın yadsınamaz gerçeğidir. Frankl (1994) anlam arayışının insanlar için temel motivasyon kaynağı olduğunu ve sadece refah için değil, hayatta kalmak için de çok önemli olduğunu öne sürmüştür. Anlamın insani olarak gelişmenin merkezi bir yönü ve kişiliğin tanımlayıcı bir özelliği olduğu vurgulanmaktadır (Weinstein, Ryan ve Deci, 2012). Araştırmalar insanların hayata karşı bir amacı ve anlamı olduğunda; yaşam doyumu, olumlu etki, öznel iyi oluş, zihinsel sağlık ve duygusal sağlığa sahip olma eğiliminde olduklarını göstermiştir (Chamberlain ve Zika, 1992).

Literatür incelendiğinde duygusal zekâ ile yaşam doyumu arasında pozitif yönde anlamlı bir ilişkinin varlığını ortaya koyan birçok çalışma mevcuttur (Ardahan, 2012; Austin, Saklofske ve Egan, 2005; Bektaş, 2014; Ikız ve Kırtıl Gormez, 2010; İnci, 2014; Liu, Wang ve Lü, 2013; Palmer, Donaldson ve Stough, 2001; Sun, Wang, Kong, 2013). Bunların yanı sıra duygusal zekâ ile yaşam doyumu arasındaki ilişkide birçok farklı değişkenin aracı rolü incelenmiştir. Örneğin; Kong, Zhao ve You (2012) duygusal zekâ ile yaşam doyumu arasında sosyal destek ve özgüvenin; Largen (2004) stresin, Bahram (2007) esnekliğin aracı rolünü incelemiş ve bu değişkenlerin tam aracı rol üstlendiklerini 
ortaya koymuşlardır. Yine duygusal zekâ, yaşam doyumu ve çeşitli değişkenler arasındaki ilişkileri ortaya koyan çalışmalarda mevcuttur. Urquijo, Extremera ve Villa (2016) yaşam doyumu ve duygusal zekâ ile psikolojik iyi oluş; Cazan ve Nastasa (2015) tükenmişlik; MontesBerges ve Augusto-Landa (2014) duygu yoğunluğu ve psikolojik iyi oluş; Rey, Extremera ve Pena (2011) benlik saygısı; Wing, Schutte, and Byrne (2006) olumlu deneyimleri yazma arasındaki ilişkiler incelemiş ve pozititif yönde anlamlı ilişkiler ortaya koymuşlardır.

Duyguları anlama, duyguları bilişsel süreçlerde kullanabilme ve yönetebilme becerisi duygusal zekânın temelini oluşturmaktadır (Mayer ve Salovey, 1997). Bu konuda Seligman ve Csikszentmihalyi (2000) pozitif psikolojinin bireysel düzeyde olumlu öznel deneyimlere bağlı olarak; geçmişte iyi oluş, hoşnutluk ve doyum; gelecekte umut ve iyimserlik; bugünde ise akış ve mutlulukla ilgili olduğunu vurgulamışlardır. Ayrıca olumlu öznel deneyimlerin ise yaşam kalitesini arttırma ve hayatın anlamsız olduğunun düşünüldüğü anlarda ortaya çıkabilen psikopatolojileri önleyebileceği öne sürülmektedir.

Bir bireyin yaşam doyumu düzeyi, yaşamının birçok alanını etkileyebilmektedir. Memnuniyet, üniversite öğrencileri için önemli olan bir kavramdır. Daha düşük düzeyde memnuniyet yaşayan bir üniversite öğrencisinin, olumsuz davranış sergileme (dersi takip etmeme, sosyal destek sistemini oluşturmada zorluk ya da alkol kullanımı gibi) olasılığının daha yüksek olabileceği düşünülmektedir (Largen, 2004). Yapılan çalışmalara bakıldığında duygusal zekâ ile yaşam doyumu arasındaki ilişkide yaşamda anlamın aracı rolüne ilişkin bir çalışmaya rastlanmamıştır. Bu açıdan daha önce yapılmamış olan bu çalışmanın sonuçları literatüre ve ileride yapılacak olan çalışmalara ışık tutması bakımından önemli görülmektedir. Ayrıca yaşamın anlamının kısmi ya da tam aracılığını ortaya koymanın deneysel çalışmaların kurgulanması açısından da faydalı olabileceği düşünülmektedir. Bütün bunlardan yola çıkarak bu çalışma ile üniversite öğrencilerinin duygusal zekâ ve yaşam doyumu düzeyleri arasındaki ilişkide yaşamda anlamın aracılık rolüne ilişkin modelin test edilmesi amaçlanmıştır.

\section{Yöntem}

Bu çalışma, üniversite öğrencilerinde duygusal zekâ ile yaşam doyumu arasındaki ilişkide yaşamda anlamın alt boyutları yaşamda anlamın varlığı ve yaşamda anlam arayışının aracı rolünü inceleyen nicel bir araştırmadır (Field, 2005).

\section{Çalışma Grubu}

Araştırmanın evreni, Amasya Üniversitesi Eğitim Fakültesi'nde 2018-2019 akademik yılında öğrenim görmekte olan üniversite öğrencilerinden oluşmaktadır. Bu evrenden tesadüfi örnekleme yoluyla ulaşılan 395 öğrenci araştırmanın çalışma grubunu oluşturmaktadır. Çalışma grubunu oluşturan katılımcıların yaş aralığı 17 ile 34 yaş aralığında değişmekte olup, yaş ortalamaları 20.62 (S.s: 1.78)' dir.

Tablo 1.Katılımcıların Cinsiyet ve Sınıf Düzeyi Değişkenlerine ilişskin Frekans ve Yüzdelik Değerleri

\begin{tabular}{|c|c|c|c|}
\hline Değişken & & $\mathrm{f}$ & $\%$ \\
\hline \multirow{4}{*}{ Cinsiyet } & $\mathrm{K} ı \mathrm{z}$ & 295 & 75.1 \\
\hline & Erkek & 98 & 24.9 \\
\hline & Kayıp veri & 2 & 0.5 \\
\hline & Toplam & 395 & 100 \\
\hline \multirow{5}{*}{ Sınıf Düzeyi } & 1 & 73 & 18.5 \\
\hline & 2 & 86 & 21.8 \\
\hline & 3 & 123 & 31.1 \\
\hline & 4 & 113 & 28.6 \\
\hline & Toplam & 395 & 100 \\
\hline \multirow{7}{*}{ Bölüm } & Fen Bilgisi Öğretmenliği & 70 & 17.7 \\
\hline & İngilizce Öğretmenliği & 24 & 6.1 \\
\hline & Rehberlik ve Psikolojik Danışmanlık & 131 & 33.2 \\
\hline & Sınıf Öğretmenliği & 84 & 21.3 \\
\hline & Sosyal Bilgiler Öğretmenliği & 21 & 5.3 \\
\hline & Türkçe Öğretmenliği & 65 & 16.5 \\
\hline & Toplam & 395 & 100 \\
\hline
\end{tabular}

Tablo 1'de görüldüğü üzere, katılımcıların \%74.7'si ( $n=295)$ kadın ve \%24.8' i ( $n=98)$ erkektir. Katılımcıların sınıf düzeylerine ilişkin oranlara bakıldığında, birinci sınıfa devam edenlerin oranı \% 18.5 ( $n=73$ ), ikinci sınıfa devam edenlerin \% 21.8 ( $n=86$ ), üçüncü sınıfa devam edenlerin \% 31.1 ( $n=123$ ) ve dördüncü sınıfa devam edenlerin \% 28.6 $(n=113)$ olduğu görülmektedir. Araştırmaya katılan üniversite öğrencilerinin okudukları bölümlerin dağılımlarına 
bakıldığında örneklemin \%33.2'sinin ( $n=131$ ) Rehberlik ve Psikolojik Danışmanlık Bölümü'nde, \% 21.3'ü ( $n=84$ ) Sınıf Öğretmenliği'nde, \% 17.7'si ( $n=70$ ) Fen Bilgisi Öğret-menliği'nde, \% 16.5'i ( $n=65$ ) Türkçe Öğretmenliği'nde \% 6.1'i $(n=24)$ İngilizce Öğretmenliği'nde ve \% 5.3'ü $(n=21)$ Sosyal Bilgiler Öğretmenliği'nde öğrenim gördüğü belirlenmiştir.

\section{Veri Toplama Araçları}

Bu araştırmada katılımcıların duygusal zekâ, yaşamın anlamı ve yaşam doyumu düzeyleri hakkında bilgi almak amacıyla Kişisel Bilgi Formu, Schutte Duygusal Zekâ Ölçeği, Yaşamın Anlamı Ölçeği ve Yaşam Doyumu Ölçeği kullanılmıştır.

Kişisel Bilgi Formu: Araştırmacılar tarafından geliştirilen Kişisel Bilgi Formu, katılımcıların sosyo-demografik özellikleri (cinsiyet, yaş, sınıf düzeyi ve okudukları bölüm) hakkında bilgi edinmek üzere oluşturulan soruları içermektedir.

Schutte Duygusal Zekâ Ölçeği: Katılımcıların duygusal zekâ düzeylerini belirlemek amacıyla Schutte v.d. (1998) yılında geliştirilen ve Austin, Saklofske ve Egan (2005) tarafından revize edilen Duygusal Zekâ Ölçeği' nin uyarlama çalışması Göçet (2006) tarafından yapılmıştır. Duygusal Zekâ Ölçeği iyimserlik, duygulardan faydalanma ve duyguların ifadesi olmak üzere üç alt boyuttan oluşmaktadır. $5^{\prime} l i$ likert tipindeki ölçekte yüksek puan ilgili alt boyutun yüksek olduğuna işaret etmektedir. Ölçeğin yapı geçerliliğini belirlemek üzere KMO örneklem uygunluk katsayıları ve Barlett Sphericity testi gerçekleştirilmiş, KMO katsayısı .79 bulunurken, Bar-lett Sphericity testi sonuçları anlamlı bulunmuştur $(x 2=2955.95, p<.001)$. Daha sonra gerçekleştirilen faktör analizinde ölçeğin üç faktörlü yapısına ulaşılmış ve faktörlerin toplam varyansın \%60'ını açıkladığı bulunmuştur. Kapsam geçerliliğimi belirlemek üzere uzman geçerliliğine başvurulmuştur. Güvenirlik çalışmalarına bakıldığında, test tekrar test ve madde toplam test korelasyonlarına bakılmıştır. Madde toplam test korelasyonlarının .22 ile .50 arasında değiştiği, test tekrar test güvenirlik katsayısının .63 olduğu görülmüştür. Son olarak cronbach alfa iç tutarlıık katsayısı $(\alpha) .78$ olarak hesaplanmıştır. Schutte Duygusal Zekâ Ölçeği'nin bu çalışma için hesaplanan cronbach alfa iç tutarlılık katsayısı ( $\alpha$ ) .83'tür.

Yaşam Doyumu Ölçeği: Diener (1984) tarafından geliştirilen ve Köker (1991) tarafından Türkçe'ye uyarlanan Yaşam Doyumu Ölçeği beş maddeden oluşmaktadır. 7'li likert tipindeki bu ölçekten alınan yüksek puan yüksek yaşam doyumuna işaret etmektedir. Çeviri çalışmaları alan uzmanları tarafından yapılan ölçek, anlaşıırlığı test edilmek üzere uygulanmıştır. Güvenirlik çalışmalarında Test Tekrar test güvenirliği ve madde toplam test korelasyonlarına bakılmıştır. Test tekrar test katsayısı .85 olarak hesaplanırken, madde korelasyonlarının .71 ile .80 arasında değiştiği görülmüştür. Yaşam Doyumu Ölçeği' nin bu çalışma için hesaplanan cronbach alfa iç tutarlııı katsayısı $(\alpha) .81^{\prime}$ 'dir.

Yaşamın Anlamı Anketi: Steger, Frazier, Oishi ve Kaler (2006) tarafından geliştirilen ve Dursun (2012) tarafından Türkçe'ye uyarlanan Yaşamın Anlamı Anketi on maddeden oluşan ve 7'li likert tipinde bir ölçektir. Yaşamın Anlamı Anketi'nin yaşamda anlam arayışı ve yaşamında anlamın varlığı olmak üzere iki alt boyutu bulunmaktadır. Ölçeğin çeviri çalışmaları alan uzmanları ve İngilizce tercümanı tarafından yapılmıştır. Yapı geçerliğinin test etmek üzere açımlayıcı ve doğrulayıcı faktör analizi uygulanmıştır. Açımlayıcı faktör analizinden elde edildiği üzere faktörlerin toplam varyansın \%56.57'sini açıkladığı tespit edilmiştir. Doğrulayıcı faktör analizi sonu elde edilen uyum indekslerinin yeterli olduğu görülmüştür $(\chi 2(34, \mathrm{~N}=317)=59.360, \mathrm{p}<0.001 ; \chi 2$ /df = 1.746; GFI = 0.94; AGFI = 0.94; RMSEA = 0.049 ve CFI $=0.98$ ). Anketin güvenirliğinin hesaplanmasında madde toplam test korelasyonu, cronbach alfa iç tutarlıık katsayısı ve test tekrar test güvenirliği kullanılmıştır. Ölçeğin madde toplam test korelasyon katsayıları .63 ile .74 arasında değişmekte olup, cronbach alfa iç tutarlılık katsayısı $(\alpha) .87$ ve test tekrar test katsayıları .81 ile .84 arasında değişmektedir. Yaşamın Anlamı Anketi'nin bu çalışma için hesaplanan cronbach alfa iç tutarlııı katsayısı ( $\alpha$ ) .73'tür.

\section{İstatistiksel Analiz}

Tüm istatistiksel işlemler SPSS 20.0 programında gerçekleştirilmiştir. İstatistiksel analizler gerçekleştirilmeden önce verilerin doğruluğunu, kayıp ve aykırı değerler ve kullanılan istatistiksel analizlerin varsayımları Tabachnick ve Fidell (2014)'in önerileri doğrultusunda incelenmiştir. Verilerin doğruluğunu incelemek amacıyla her bir değişkenin frekans dağılımları incelenmiş ve tüm değişkenlerin frekans dağılımlarının beklenen değer aralığında olduğu görülmüştür. Veri setindeki kayıp değerler incelendiğinde her bir değişkendeki kayıp değer miktarını \% 0 ile \% 1 arasında değiştiği görülmüştür. Bu sınırlı sayıdaki kayıp değerden biri olan Duygusal Zekâ Ölçeği'ndeki bir değere beklenti maksimizasyon algoritması kullanılarak veri atama işlemi gerçekleştirilmiştir. Tabachnick ve Fidell (2014)' e göre veri setindeki kayıp değer miktarı \%5 ve altında olduğunda bu değer önemsiz bir miktardır ve bu değer farklı veri atama türlerine benzer sonuçlar verme eğilimindedir. Kayıp değerlerin atanmasını takiben veri setindeki tek değişkenli ve çok değişkenli aykırı değerler incelenmiştir. Duygusal Zekâ Ölçeği'nde bir tek değişkenli aykırı değer tespit edilerek veri setinden çıkarılmıştır. Aynı zamanda çok değişkenli aykırı değerlerin incelenmesi sonucunda on iki çok değişkenli 
aykırı değer veri setinden çıkarılmıştır. Araştırmada kullanılacak istatistiklerin gerçekleştirilmesinden önce verilerin normallliğine ilişkin incelemelerde çarpıklık ve basıklık değerlerinin +2 ila -2 aralığında olduğu ve verilerin normale yakın bir dağılım gösterdiği görülmüştür. Katılımcıların sosyodemografik özellikleri hakkında bilgi vermek amacıyla betimsel istatistiklerden yararlanılmıştır. Tüm değişkenler arasındaki ilişkiler Pearson Korelasyon Katsayısı ve Hiyerarşik Regresyon analizi aracılığılla incelenmiştir. Son olarak elde edilen veriler doğrultusunda Yaşamın Anlamı Ölçeği boyutlarından Yaşamda Anlamın Varlığı boyutunun aracı rolü SPSS Process makrosu Model 4 ile test edilmiştir. İstatistiksel analizlerde hipotezlerin test edilmesinde .05 anlamlılık düzeyi kullanılmıştır.

\section{Prosedür}

Araştırmaya konu olan verilerin toplanması ve değerlendirilmesi Aralık 2018-Şubat 2018 tarihleri arasında gerçekleştirilmiştir. Uygulamalar araştırmacılar tarafından Amasya Üniversitesi Eğitim Fakültesi'ne devam etmekte olan öğrencilere sınıf ortamında gerçekleştirilmiştir. Katılımın gönüllüğü esas alınmış ve verilen yanıtların gizliliğinin korunacağı belirtilmiştir. Katılımcılar veri toplama araçlarını yaklaşık 20 dakikada yanıtlamışlardır.

\section{Bulgular}

Tablo 2'de değişkenler arasındaki korelasyon katsayıları ve değişkenlerin ortalama ve standart sapma değerleri görülmektedir.

Tablo 2. Değişkenler Arasındaki Korelasyon Katsayıları ve Değişkenlerin Ortalama ve Standart Sapma Değerleri

\begin{tabular}{lllll}
\hline & \multicolumn{1}{c}{1} & \multicolumn{1}{c}{2} & \multicolumn{1}{c}{3} & \multicolumn{1}{c}{4} \\
\hline 1. Yaşam Doyumu & - & & & \\
2. Duygusal Zekâ & $.321^{* *}$ & - & & \\
3. Yaşamda Anlamın Varlığı & $.617^{* *}$ & $.431^{* *}$ & - & \\
4. Yaşamda Anlam Arayışı & $-.152^{* *}$ & .047 & $-.133^{* *}$ & - \\
Ort. & 22.09 & 156.44 & 25.80 & 25.33 \\
Ss & 6.04 & 14.33 & 6.44 & 6.63 \\
\hline
\end{tabular}

Not. ${ }^{* *} \mathrm{p}<.01$

Tablo 2' den elde edilen bilgiye göre, duygusal zekâ yaşam doyumu, yaşamda anlamın varlığı arasında po-zitif yönlü anlamlı ilişkiler bulunurken ( $p<.01$ ); yaşamda anlam arayışı ile arasında anlamlı ilişkiye rastlanmamıştır. Yaşamda anlamın varlığı yaşam doyumu ile pozitif ilişkili bulunurken; yaşamda anlam arayışı ile yaşam doyumu arasında negatif yönlü anlamlı ilişkilere rastlanmıştır $(p<.01)$.

Yaşamda anlamın varlığı boyutunun duygusal zekâ ile yaşam doyumu arasındaki ilişkide aracı rolünü belirleyebilmek amacıyla bir dizi regresyon analizi gerçekleştirilmiştir. Gerçekleştirilen birinci ve ikinci aşama basit regresyon analizi sonuçları Tablo 3'te sunulmuştur (Birinci-ikinci Adım).

Tablo 3. Yaşam Doyumu Yordanan Değişkenine ilişkin Birinci ve íkinci Aşama Basit Doğrusal Regresyon Analizi Sonuçları

\begin{tabular}{|c|c|c|c|c|c|c|}
\hline \multirow[t]{2}{*}{ Model } & & \multicolumn{2}{|c|}{ Standardize Edilmemiş } & \multirow{2}{*}{$\begin{array}{l}\text { Standardize Katsayılar } \\
\beta\end{array}$} & \multirow[t]{2}{*}{$t$} & \multirow[t]{2}{*}{$p$} \\
\hline & & $B$ & $\mathrm{SH}$ & & & \\
\hline \multicolumn{7}{|c|}{ YAV-Aşama 1} \\
\hline \multirow[t]{2}{*}{ Model 1} & (Sabit) & -4.50 & 3.22 & & -1.401 & .16 \\
\hline & Duygusal Zekâ & .19 & .02 & .43 & 9.47 & $.001^{*}$ \\
\hline \multicolumn{7}{|c|}{ YD-Aşama 2} \\
\hline \multirow[t]{2}{*}{ Model 1} & (Sabit) & .92 & 3.16 & & .291 & .77 \\
\hline & Duygusal Zekâ & .14 & .02 & .32 & 6.73 & $.001^{*}$ \\
\hline \multicolumn{7}{|c|}{ YD-Aşama 2} \\
\hline \multirow[t]{2}{*}{ Model 1} & (Sabit) & 7.19 & .99 & & 7.26 & .000 \\
\hline & YAV & .58 & .04 & .62 & 15.52 & $.001^{*}$ \\
\hline
\end{tabular}

Not. ${ }^{*} p<.001$.

Yaşamda anlamın varlığının duygusal zekâ ile yaşam doyumu arasındaki ilişkide aracı rolünü tespit etmek amacıyla yapılan birinci basit doğrusal regresyon analizinde, duygusal zekânın yaşamda anlamın varlığını $(F(1,393)=89.62, p<$ $.001, R=.43, R 2=.19, R 2$ adj $=.18)$ ve yaşam doyumunu $(F(1,393)=45.24, p<.001, R=.32, R 2=.10, R 2$ adj $=.10)$ anlamlı bir şekilde yordadığı bulunmuştur. Yaşamda anlamın varlı̆̆ının yaşam doyumunu anlamlı bir şekilde yordadığı 
bulunmuştur $(F(1,393)=240.96, p<.001, R=.62, R 2=.38, R 2 a d j=.38)$ Analizlerin ikinci aşamasında yaşamda anlamın varlığının, duygusal zekâ ve yaşam doyumu arasındaki ilişki-de aracı rolünü test etmek amacıyla hiyerarşik regresyon analizi gerçekleştirilmiştir (Tablo 4).

Tablo 4. Yaşam Doyumu Yordanan Değişkenine ilişkin Gerçekleştirilen Hiyerarşik Regresyon Analizi Sonuçları

\begin{tabular}{|c|c|c|c|c|c|c|c|c|c|c|}
\hline \multirow{2}{*}{ Değişken } & \multicolumn{5}{|c|}{ Adım 1} & \multicolumn{5}{|c|}{ Adım 2} \\
\hline & $B$ & Sh & $\beta$ & $t$ & $p$ & $B$ & Sh & $\beta$ & $t$ & $p$ \\
\hline \multicolumn{11}{|l|}{ YD } \\
\hline Sabit & 7.19 & .99 & & 7.26 & $.001^{*}$ & 3.40 & 2.63 & & 1.29 & .20 \\
\hline YAV & .58 & .04 & .62 & 15.52 & $.001 *$ & .55 & .04 & .59 & 13.36 & .12 \\
\hline $\mathrm{DZ}$ & & & & & & .03 & .02 & .07 & 1.56 & $.001^{*}$ \\
\hline
\end{tabular}

Not. ${ }^{*} p<.001$.

Tablo 4'te görüldüğü gibi yaşamın anlamının varlığı değişkeni ikinci aşamada regresyon analizine girildiğinde duygusal zekâ değişkeninin yaşam doyumu değişkeni için artık anlamlı bir yordayıcı olmadığı görülmüştür. Bu durum yaşamın anlam varlığının, duygusal zekâ ile yaşam doyumu arasındaki ilişkide tamamen aracı bir değişken olduğunu göstermektedir. Aynı zamanda Bootstrap analizine ilişkin sonuçlar dolaylı etkinin anlamlı olduğunu göstermiştir. Yaşamda anlamın varlığının, duygusal zekâ ve yaşam doyumu ilişkideki aracı rolü Şekil 1'de görülmektedir.

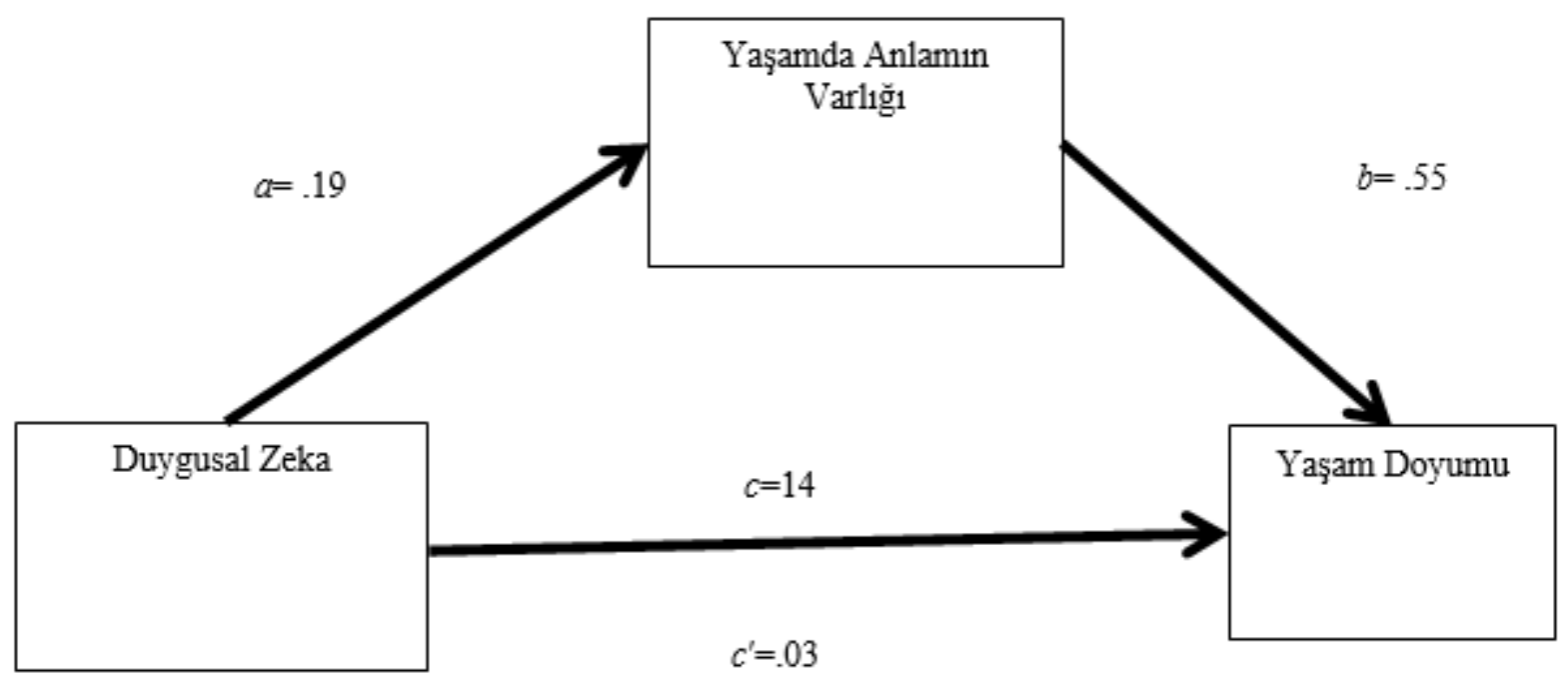

Şekil 1: Yaşamda Anlamın Varlığı'nın Duygusal Zekâ ve Yaşam Doyumu Arasındaki iliş̧kide Aracı Rolü (p< .001).

Şekil 1'de görüldüğü gibi duygusal zekânın yaşam doyumu giden yol katsayısının (c) .14 (p<.001) olduğu ancak yaşamda anlamın varlığı aracı değişkeni modele eklendiğinde bu katsayının (c') .03'e (p<.001) düştüğü-nü göstermektedir. Aracı değişken olan yaşamda anlamın varlığı modele eklendiğinde duygusal zekânın yaşam doyumu üzerindeki direkt etkisi olarak da adlandırılan bu katsayının (c') istatistiksel olarak anlamlı kalmakla birlikte önemli bir miktar düşüş göstermesi tam aracılığın önemli bir göstergesidir (Hayes, 2009).

\section{Sonuçlar}

Bu araştırmada, duygusal zekâ ile yaşam doyumu arasındaki ilişkide yaşamın anlamı boyutlarından ya-şamda anlamın varlığı ve yaşamda anlam arayışının aracı rolünü incelenmiştir. Elde edilen korelasyon değerlerinde duygusal zekâ ile yaşamın anlamı alt boyutlarından yaşamda anlam arayışı arasında ilişkinin bulunmadığı görülmüştür. Araştırma sonuçları, duygusal zekâ ile yaşam doyumu arasındaki ilişkide yaşamda anlamın varlığı boyutunun aracı rolüne dayalı incelemede, duygusal zekâ ile yaşam doyumu arasındaki ilişkide yaşamda anlamın varlığının tam aracı bir değişken olduğu görülmüştür. Bu sonuçlara göre, üniversite öğrencilerinden duygusal zekâ düzeyleri yüksek olanlarının yaşamda anlamın varlığı düzeylerinin ve yaşam doyumlarının daha yüksek olduğu belirlenmiştir.

Bu çalışmanın sonucuyla birebir örtüşen bir bulguya rastlanmamıştır. En benzer olarak Teques, Carrera, Ribeiro, Teques ve Ramon (2016) "Psikoonkolojide duygusal zekâ ve yaşamın anlamının önemi" başlıklı makalelerinde duygusal zekâ, yaşam doyumu ve yaşam amacı/anlamı arasındaki ilişkiyi kanser hastası olan ve olmayan hastalar üzerinde incelemişlerdir. Araştırma sonucunda kanser hastası olanların duygusal zekâ ve yaşamın anlamı düzeyleri 
arasında, kanser hastası olmayanlara göre daha anlamlı bir ilişkinin olduğu ortaya konmuştur. Ayrıca duygusal zekânın alt boyutlarından bazıları ile yaşamın anlamının alt boyutları arasında pozitif yönde ilişkilerin olduğu görülmüştür. Yine genel popülasyonda yaşamın anlamının alt boyutları ile yaşam doyumu alt boyutları arasındaki anlamlı ilişkiler araştırmanın diğer bulgularındandır. Elde edilen sonuçlar doğrultusunda; duygusal zekâ, yaşam doyumu ve yaşam amacı arasındaki yakın ilişkiler gösterilerek pozitif psikolojinin önemi vurgulanmış ve iyi bir yaşam sürmek için bu değişkenlerin ele alınması gerektiği dile getirilmiştir. Başka bir çalışmada Yıkılmaz ve Güdül (2015) üniversite öğrencileri üzerinde yapmış oldukları araştırmalarında anlam arayışının yaşam doyumunun önemli bir yordayıcısı olmadığı; fakat yaşamda anlam varlığının yaşam doyumunun anlamlı bir yordayıcısı olduğu ortaya konmuştur. Duygusal zekâ kavramı hem kendi duygularını, hem başkalarının duygularını anlamlandırıp çevresel ilişkilerde sağlıklı kararlar alabilmeyi içeren bir kavramdır. Yaşam doyumu kişinin yaptıklarından maddi ve manevi boyutta haz almasıdır. Yaşamın anlamı ise kişinin kendisini ve başkalarını en iyi şekilde anlayıp, ilişkilerinde sağlıklı kararlar verip, hedeflerini bu kararlar doğrultusunda belirleyen, kararlarından memnun olarak yaşamından keyif alabilmesini içerir. Bu açılardan bakıldı̆̆ında aslında bu kavramların birbirlerini kapsadığı söylenebilir. Araştırmadan elde edilen bulgu açısından bakıldığında birbirleri ile bu kadar iç içe olan kavramlar arasında pozitif yönde ilişkilerin olması birbirinden farkı görünse de aslında içerik ve varılmak istenen sonuç açısından (daha sağlıklı ilişkiler ve daha mutlu bir yaşam) birbirlerini oldukça destekleyen kavramlar olduğu şeklinde yorumlamak mümkündür.

Araştırmanın çalışma grubunu oluşturan üniversite öğrencilerinin duygusal zekâ düzeylerinin arttıkça yaşam doyumlarının artacağı; buna bağlı olarak yaşamda anlamın varlığının da yükseleceği düşünülmektedir. Duygusal zekânın temelinde duyguları (olumlu veya olumsuz) etkili bir şekilde yönetebilmek; yaşam doyumunun özünde ise kişinin yaşadığı hayatı (iyisiyle kötüsüyle) kabullenip kendini iyi hissetmek olduğu düşünülebilir. Bu açıdan bakıldığında duygularını iyi yönetebilen, yaşanılan olumsuzluklarda kolay kolay pes etmeyen kişilerin yaşam doyumlarının da daha yüksek olacağı varsayılmaktadır. Duygusal zekâ ve yaşam doyumu birbirini besleyen birbirleri ile ilişkili ve pozitif yönlü bir korelasyona sahip olan iki değişkendir. Duygusal zekâ ve yaşam doyumu arasındaki anlamlı ilişkileri ortaya koyan birçok çalışma mevcuttur (Ardahan, 2012; Austin, Saklofske ve Egan, 2005; Bektaş, 2014; Ikız ve Kırtıl Gormez, 2010; Inci, 2014; Liu, Wang ve Lü, 2013; Palmer, Donaldson ve Stough, 2001; Sun, Wang, Kong, 2013). Bu araştırma bulgusu duygularını en sağlıklı şekilde yönetebilen kişinin yaşamında aldığı kararların sonucu ne olursa olsun arkasında durabilen, kabullenen ve olumsuz sonuçları yani krizleri daha iyi atlatabilen bireylerin yaşamından daha fazla doyum alacağı ve her yaşanılanı olgunlukla karşılayıp daha anlam dolu bir yaşam sürebileceği şeklinde yorumlanabilir. Bu yönleri ile bu iki kavram arasındaki ilişkilerin araştırılması ve bunlara ek olarak aralarında aracı rol oynayan değişkenlere odaklanılmasının daha sağlıklı düşünebilen ve hissedebilen, hayata daha pozitif bakabilen bir neslin gelişimi için etkili olacağı düşünülmektedir Bu yüzden duygusal zekâ ve yaşam doyum düzeylerini arttırmaya yönelik yapılacak olan çalışmaların aynı zamanda daha anlamlı bir hayat, daha olumlu bir bakış açısı ve tüm bunlara bağlı olarak daha mutlu bireyler yetişmesi beklenmektedir.

Sonuç olarak, bu çalışmada duygusal zekâ ile yaşam doyumu arasındaki ilişkide yaşamda anlamın varlığının tam aracı bir değişken olduğu görülmüştür. Bu sonuçlara göre, duygusal zekâ düzeyi yüksek olan üniversite öğrencilerinin yaşamda anlama sahip olma olasılıklarının yüksek ve yaşam doyumu puanlarının yüksek olduğu bulunmuştur. Başka bir ifadeyle, duygusal zekâ düzeyinin yüksek oluşu üniversite gençliğinin hem yaşamada anlama sahip olmalarına olumlu etki yaparak yaşamdan daha fazla keyif almalarına yardımcı olmaktadır.

\section{5. Öneriler}

Bu araştırma üniversite düzeyinde eğitim almakta olan genç yetişkin bireylerle sınırlıdır. Bu çalışma grubu Türkiye örnekleminde aynı yaş grubunda ancak farklı eğitim düzeylerine sahip bireylere genellenebilirliği düşündürücüdür. Benzer bir şekilde incelenen modelin farklı yaş gruplarındaki örneklemlerde de ele alınabileceği düşünülmektedir. Elde edilen sonuçlar doğrultusunda duygusal zekâyı geliştirmeye yönelik gerçekleştirilecek grup çalışmalarının yaşamda anlama sahip olmayı ve dolayısıyla yaşam doyumunu olumlu etkileyeceği ve böylelikle olası ruh sağlığı risklerine karşı koruyucu faktörleri arttırabileceği düşünülmektedir. Bu nedenle duygusal zekâyı geliştirmeye yönelik deneysel desende geliştirilecek çalışmaların yaşam doyumu ve yaşamdaki anlama etkileri incelenebilir. Ülkemizde duygusal zekâ ve yaşam doyumu oldukça ele alınan konular olmalarına karşın, yaşamda anlamın değerlendirilmesine ilişkin çalışmaların kısıtı olduğu görülmektedir. Yaşamda anlam konusunda yapılan çalışmaların daha çok yetişkinler üzerinde yapıldığı gözlenmiştir. Bu nedenle yaşamda anlamın farklı yaş gruplarında niceliksel veya niteliksel olarak incelenmesinin her yaş döneminde yaşamın farklılaşan anlamına ilişkin bilgi sağlayabileceği gibi, her dönemde ortaya çıkabilen uyum problemlerini en aza indirgemeyi hedefleyen çalışmalar yapılabilir. 


\section{Kaynakça}

Ardahan, F. (2012). Duygusal zekâ ve yaşam doyumu arasındaki ilişkinin doğa sporu yapanlar örneğinde incelenmesi. Pamukkale Üniversitesi Spor Bilimleri Dergisi, 3(3), 20-33. Retrieved from http://dergipark.gov.tr/psbd/issue/20578/219265.

Austin, E. J., Saklofske, D. H., \& Egan, V. (2005). Personality, well-being and health correlates of trait emotional intelligence. Personality and Individual Differences, 38(3), 547-558. doi: 10.1016/j.paid.2004.05.009.

Bahram, J. (2007). The mediating role of resilience in the relationship between general and emotional intelligence and life satisfaction. Contemporary Psychology, 2(4), 3-12.

Bektaş, E. (2014). Üniversite öğrencilerinde duygusal zekâ ve yaşam doyumu ilişkisi (Facebook kullananlar üzerine bir araştırma) (Yüksek lisans tezi), Toros Üniversitesi Sosyal Bilimler Enstitüsü, Mersin.

Bilir, N. ve Subaşı, N. P. (2006). Yaşlııı sorunları. Ç. Güler ve L. Akın (Ed.). Halk sağlığı temel bilgiler. (ss. 1020-1031). Ankara: Hacettepe Üniversitesi Yayınları.

Cazan, A.-M., \& Nastasa, L. E. (2015). Emotional intelligence, satisfaction with life and burnout among university students. Procedia - Social and Behavioral Sciences, 180, 1574-1578. doi: 10.1016/j.sbspro.2015.02.309.

Chamberlain, K., \& Zika, S. (1992). Religiosity, meaning in life, and psychological wellbeing. In J. F. Schumaker (Ed.), Religion and mental health (pp. 138-148). New York, NY: Oxford University Press.

Clonan, S. M., Chafouleas, S. M., McDougal, J. L., \& Riley-Tillman, T. C. (2004). Positive psychology goes to school: are we there yet?. Psychology in the Schools, 41(1), 101-110. doi: 10.1002/pits.10142.

Diener, E. (1984). Subjective well-being. Psychological Bulletin, 95(3), 542-575. Retrieved from https://ssrn.com/abstract=2162125.

Donaldson, S. I., Csikszentmihalyi, M., \& Nakamura, J. (2011). Applied positive psychology: Improving Everyday life, health, schools, work, and society. Hoboken: Taylor \& Francis.

Dursun, P. (2012). The role of meaning in life, optimism, hope, and coping styles in subjective well-being (Doctoral thesis), Middle East Technical University The Graduate School Of Social Sciences, Ankara.

Emir, S. (2013). Öğretmenlerin düsünme stillerinin eleştirel düsünme eǧilimlerini yordama gücü (i̇stanbul-Fatih örneği). Kuram ve Uygulamada Eğitim Bilimleri (KUYEB), 13(1), 337-347.

Field, A. (2005). Discovering statistics using SPSS (2. Edition). London, Thousand Oaks, New Delhi: Sage Publications.

Frankl, V. E. (1994). Duyulmayan anlam çığlığı. psikoterapi ve hümanizm. Ankara: Öteki Yayınevi.

Goleman, D. (2010). Emotional intelligence: Why it can matter more than IQ. London: Bloomsbury.

Göçet, E. (2006). Üniversite öğrencilerinin duygusal zekâ düzeyleri ile stresle başa çıkma tutumları arasındaki ilişki (Yüksek lisans tezi), Sakarya Üniversitesi Sosyal Bilimler Enstitüsü, Sakarya.

Hayes, A.F. (2009). Beyond Baron and Kenny: Statistical mediation analysis in the new millennium. Communication Monographs, 76(4), 408-420.

Ikız, F. E., \& Kırtıl Gormez, S. (2010). İlköğretim ikinci kademe öğrencilerinde duygusal zekâ ve yaşam doyumunun incelenmesi. Elementary Education Online, 9(3), 1216-1225.

İnci, S. (2014). Aday öğretmenlerin duygusal zekâ ile yaşam doyumu düzeyleri arasındaki ilişki (Yüksek lisans tezi). Çanakkale Üniversitesi Eğitim Bilimleri Enstitüsü, Çanakkale.

Kong, F., Zhao, J., \& You, X. (2012). Emotional intelligence and life satisfaction in Chinese university students: The mediating role of self-esteem and social support. Personality and Individual Differences, 53(8), 1039-1043. doi: 10.1016/j.paid.2012.07.032.

Köker, S. (1991). Normal ve sorunlu ergenlerin yaşam doyumu düzeyinin karşılaştırılması (Yüksek lisans tezi), Ankara Üniversitesi Sosyal Bilimler Enstitüsü, Ankara.

Largen, J. E. (2004) The relationship between stress, satisfaction, and emotional intelligence in college students (Master's thesis). Western Kentucky University Masters Theses \& Specialist Projects. Paper 533. Retrieved from http://digitalcommons.wku.edu/theses/533 
Linley, A. (2009). Positive psychology (history). In S. Lopez (ed.) In The encyclopedia of positive psychology (pp. $742-$ 746). Chichester: Blackwell Publishing Ltd.

Liu, Y., Wang, Z., \& Lü, W. (2013). Resilience and affect balance as mediators between trait emotional intelligence and life satisfaction. Personality and Individual Differences, 54(7), 850-855. doi: 10.1016/j.paid.2012.12.010.

Maddux, J. E. (2018). Subjective well-being and life satisfaction: An introduction to conceptions, theories, and measures. In J. E. Maddux (Ed.), Frontiers of social psychology. Subjective well-being and life satisfaction (pp. 3-31). New York, NY, US: Routledge/Taylor \& Francis Group.

Mayer, J. D., \& Salovey, P. (1997). What is emotional intelligence? In P. Salovey \& D. Sluyter (Eds.), Emotional development and emotional intelligence: Educational implications (pp. 3-31). New York: Basic Books.

Montes-Berges, B., \& Augusto-Landa, J. M. (2014). Emotional intelligence and affective intensity as life satisfaction and psychological well-being predictors on nursing professionals. Journal of Professional Nursing, 30(1), 8088. doi: 10.1016/j.profnurs.2012.12.012.

Moore, A (2018, April 23). This happiness course is the most popular class in Yale's history. Retrieved from https://www.weforum.org/agenda/2018/04/happiness-101-psychology-course-strikes-chord-with-yalestudents (2019, April 1).

Palmer, B., Donaldson, C., \& Stough, C. (2002). Emotional intelligence and life satisfaction. Personality and Individual Differences, 33(7), 1091-1100. doi: 10.1016/S0191-8869(01)00215-X.

Parker, J. D. A., Saklofske, D. H., Wood, L. M., \& Collin, T. (2009). The role of emotional intelligence in education. In C. Stough, D. H. Saklofske \& J. D. A. Parker (Eds.), Assessing emotional intelligence: theory, research, and applications (pp. 239-255). Boston, MA: Springer-Verlag US.

Paschali, A., \& Tsitsas, G. (2010). Stress and life satisfaction among university students-a pilot study. Annals of General Psychiatry, 9(1). doi: 10.1186/1744-859X-9-S1-S96.

Rey, L., Extremera, N., \& Pena, M. (2011). Perceived emotional intelligence, self-esteem and life satisfaction in adolescents. Psychosocial Intervention, 20(2), 227-234. doi: 10.5093/in2011v20n2a10.

Schutte, N. S., Malouff, J. M., Hall, L. E., Haggerty, D. J., Cooper, J. T., Golden, C. J., \& Dornheim, L. (1998). Development and validation of a measure of emotional intelligence. Personality and Individual Differences, 25(2), 167-177. doi: 10.1016/S0191-8869(98)00001-4.

Seligman, M. E. P., \& Csikszentmihalyi, M. (2000). Positive psychology: an introduction. American Psychologist, 55(1), 5 - 14. doi: 10.1037/0003-066X.55.1.5.

Steger, M. F., Frazier, P., Oishi, S., \& Kaler, M. (2006). The meaning in life questionnaire: Assessing the presence of and search for meaning in life. Journal of Counseling Psychology, 53(1), 80-93. doi: 10.1037/0022-0167.53.1.80.

Sun, P., Wang, S., \& Kong, F. (2014). Core self-evaluations as mediator and moderator of the relationship between emotional intelligence and life satisfaction. Social Indicators Research, 118(1), 173-180. doi: 10.1007/s11205013-0413-9.

Tabachnick, B. G., \& Fidell, L. S. (2014). Using multivariate statistics. Harlow: Pearson Education.

Teques, A. P., Carrera, G. B., Ribeiro, J. P., Teques, P., \& Ramon, G. L. (2016). The importance of emotional intelligence and meaning in life in psycho-oncology: Emotional intelligence and meaning in life. Psycho-oncology, 25(3), 324-331. doi: 10.1002/pon.3921.

Urquijo, I., Extremera, N., \& Villa, A. (2016). Emotional intelligence, life satisfaction, and psychological well-being in graduates: the mediating effect of perceived stress. Applied Research in Quality of Life, 11(4), 1241-1252. doi: 10.1007/s11482-015-9432-9.

Weinstein, N., Ryan, R. M., \& ve Deci, E. L. (2012). Motivation, meaning, and wellness, a self-determination perspective on the creation and internalization of personal meanings and life goals. In P. T. P. Wong (Ed.), The human quest for meaning, theories, research, and applications (pp. 81-106). New York: Routledge.

Wing, J. F., Schutte, N. S., \& Byrne, B. (2006). The effect of positive writing on emotional intelligence and life satisfaction. Journal of Clinical Psychology, 62(10), 1291-1302. doi: 10.1002/jclp.20292. 
Yıkılmaz, M., \& Güdül, M. D. (2015). Üniversite öğrencilerinde yaşam doyumu, yaşamda anlam ve bilinçli farkındalık arasındaki ilişkiler. Ege Eğitim Dergisi, 16(2), 297-315. doi: 10.12984/ee.09530. 